\title{
Mental Health Problems of U.S. Students Studying Abroad
}

\author{
Senel Poyrazli \\ Michael A. Mitchell \\ The Pennsylvania State University- Harrisburg, USA
}

\begin{abstract}
This study describes mental health problems and needs among a sample of college students from the United States studying abroad in Italy. Overall, students surveyed had relatively low clinical diagnostic thresholds for psychological distress. Individual symptoms were more prevalent and included difficulty sleeping, eating problems (poor appetite or overeating), irritability, and anxiety. Findings from this study offer recommendations for study abroad professionals to screen, monitor, and engage students about their mental health well-being while abroad.
\end{abstract}

Keywords: college students, mental health, study abroad

\section{INTRODUCTION}

According to the Institute of International Education (IIE, 2018) data, over 320,000 U.S. students studied abroad during the 2016-2017 academic year with the participation rate increasing each year. At the same time, however, mental health statistics show an increased need for psychiatric services across college campuses and an increase in clients with severe problems (Barr et al., 2010; Lindeman, 2016). International educators are increasingly offering subjective reports and case studies contributing to the literature about mental health abroad regarding the types of mental health issues students are facing (Lindsey \& Struve, 2008; Lucas, 2009; McCabe, 2005). For example, Lucas (2009) discussed his experiences of 13 years as a studyabroad director and how he "steadily encounter[s] more students with incapacitating mental health concerns" (p. 187), and offered recommendations about how to help these students based on his own dealings with different cases. While the literature indicates a considerable amount of research (e.g., Sandhu, 1995; Sumer et al., 2008) 
about international students' mental health, focusing on acculturation factors that can intensify psychological symptoms, such as depression or anxiety, limited discussion exists in the empirical literature regarding mental health and well-being among U.S. college students abroad (Bathke \& Kim, 2016).

In one particular study about students abroad, after reviewing forms on which students had self-disclosed personal health issues, Lindsey and Struve (2008) found that the most common mental health-related issues among study abroad students included depression, attention deficit and hyperactivity disorder, eating disorders, borderline personality disorder, and psychotic symptoms. Lucas (2009) also shared his observation that numerous study abroad students suffer from mental illnesses such as anxiety disorders and anorexia.

Similar to international students studying in the United States, U.S. students abroad may encounter stressors such as prejudice and discrimination, especially in settings where there is a negative perception of the United States and the people from the U.S. culture. In addition, psychosocial problems such as loss, separation, travel stress, social pressure, exacerbation of any pre-existing or dormant conditions, complications with medications, and unforeseen events can be triggers for students abroad (e.g., McCabe, 2005; Mikulas \& Jitka, 2019). Unforeseen events include receiving bad news from home, such as the death of a family member or close friend, terrorist attacks, national health crises and outbreaks of diseases, political violence and riots, and natural disasters (McCabe, 2005). Events of each of these types have occurred in the recent past: the SARS outbreak in Asia, terrorist attacks in London and Paris and elsewhere in the world, riots in Cairo, Egypt, and the earthquake in L'Aquila, Italy.

Despite the supporting literature about various psychosocial stressors for students abroad, very few studies document the occurrence and prevalence of mental health issues in U.S. students abroad. Preliminary research indicates that U.S. students abroad face various types of psychosocial concerns and problems. Ryan and Twibell (2000) found that the most common concerns among U.S. students studying abroad were personal adjustment, academic success, health and safety, and interpersonal communication. Also noteworthy, the authors found almost a third of students surveyed reported some type of emotional problems, including feelings of depression that interfered with their activities. Hunley (2010) hypothesized that mental health problems would deter students from studying abroad; however, her findings indicated that higher levels of depression acted as strong predictor for studying abroad. Although the small sample size limited generalizability, Hunley later hypothesized that there is a possibility that depressed students may use study abroad as an escape.

This theme of looking for adventure while escaping problems at home may fit into a larger narrative about constructing identity as one begins the transition from young adulthood to adulthood. In addition, people often see the theme of travel as a means of "finding oneself" reinforced in study abroad and popular media messaging. Frequently this quest involves leaving all of one's troubles behind and encountering a new adventure with a goal of ultimately finding a new sense of self, or even an entirely "new self" (Penn, 2007; Murphy, 2010); however, as Cushner (2004) 
poignantly reminded the traveler, "No matter where you go, you, too, will be there" (p. 6).

The lack of research in the area of study abroad participants' mental health unfortunately challenges study abroad professionals who are often the front-line people providing assistance to U.S. students abroad. The considerable research regarding international students' mental health can serve as a framework to examine psychosocial stressors that can contribute to psychological distress and mental health problems for U.S. students abroad. Moreover, as researchers interested in international students' mental health have shifted from examining sociocultural difficulties to examining the prevalence of psychological distress and their mental health needs (e.g., Hyun et al., 2007; Mori, 2000), a similar approach is needed for understanding such prevalence and needs for U.S. students studying abroad.

A considerable gap remains between dominant narratives, professional materials, and empirical evidence, which must be bridged to expand research efforts with this population and facilitate data-based decision-making by study abroad programs regarding the mental health support services that these students need. Therefore, this research study intends to expand on the limited previous research about U.S. college students by exploring the prevalence and characteristics of mental health issues in a sample of U.S. students studying abroad in Italy.

\section{METHODS}

\section{Participants}

Participants for this study included 111 undergraduate U.S. students studying abroad for a semester in Italy on programs sponsored by two northeastern U.S. universities. All participants completed a web-based assessment focused on understanding their psychosocial experiences during their Italy program. The response rate was $20 \%$. Students completed the survey on average 3-4 weeks after they started their study abroad program. The majority of these students were studying either in Rome or Florence. Survey participants mainly identified as women (76\%), White $(91 \%)$, heterosexual $(95.5 \%)$, single $(65.8 \%)$, under 21 years old $(69.4 \%)$, and in their third/junior year of college $(50.5 \%)$.

\section{Procedures}

We received Institutional Review Board approval for the study before collecting any data. We collected the survey data anonymously over four academic terms. Study abroad professionals contacted all of their students studying abroad in Italy to invite them to participate in this research project. The education abroad professionals forwarded a series of three email messages to their students. We sent the first email 2 weeks before the students left the United States to inform them about the research study. We sent the second email approximately 1 month into the students' study abroad program and asked them to fill out the survey online. We sent the final email a week after the second email, reminding the students to fill out the online survey. 


\section{Measures}

The survey was a combination of standard psychological tests that included the Patient Health Questionnaire-9 (PHQ-9; Kroenke \& Spitzer, 2002; Kroenke et al., 2001) and the Generalized Anxiety Disorder Scale-7 (GAD-7; Spitzer et al., 2006), and a set of selected items from the Center for Collegiate Mental Health's (CCMH) standardized data set. Below we present more detailed information about these questionnaires.

\section{Depression}

The PHQ-9 is a self-reporting measure consisting of nine questions that assess the severity of depression. A total score is calculated, ranging from 0 to 27 . In the present study, the severity of depression was based on the associated scoring guidelines including minimal (1-4), mild (5-9), moderate (10-14), moderately severe (15-19), and severe (20-27). Several studies have identified the PHQ-9 as a valid screening tool for depression, and it has been tested reliable with other depression assessment tools and clinical interviews in both clinical and nonclinical populations (e.g., Kroenke et al., 2001; Martin et al., 2006). The PHQ-9 has also demonstrated strong correlations with other depression scales such as the Beck Depression Inventory ( $r=.73$; Martin et al., 2006). This instrument has been widely used in a variety of populations, including college students (e.g., Cranford et al., 2009; Garlow et al., 2008; Zivin et al., 2009). Internal reliability for the current study was determined by Cronbach's alpha $(\alpha=.73$; the ninth item on suicidal thoughts was excluded because no participants endorsed this item).

\section{Anxiety}

The GAD-7 assesses generalized anxiety, panic, and posttraumatic stress disorders. Each of the seven items on this measure assesses the level of distress on a 4-point Likert scale ranging from 1 (not at all) to 4 (nearly every day). A total score is calculated, ranging from 0 to 21 . The identified cut-off points provided in the instrument manual were used to identify minimal (1-4), mild (5-9), moderate (10$14)$, and severe (15-21). The GAD-7 has been found to have excellent reliability (Cronbach's $\alpha=.92)$ and good test-retest reliability ( $r=.83$; Spitzer et al., 2006). In a sample of primary care patients, the scale demonstrated validity diagnostic criterion, construct, and procedural and factorial validity (Spitzer et al., 2006). This instrument has recently been used with college students, particularly with a sample of student veterans, and has demonstrated excellent reliability within this sample $(\alpha=.95$; Rudd et al., 2011). Internal consistency for this study was good (Cronbach's $\alpha=.85$ ).

\section{Previous Mental Health History}

We used selected items from the CCMH (2010) standardized data set to collect information about respondents' previous mental health history. These items included 
previous mental health treatment, current mental health treatment, suicidal ideation and behaviors, nonsuicidal self-injurious behaviors, and history of previous trauma.

\section{Data Analysis}

We used descriptive analyses to report frequencies and measures of central tendency (e.g., mean, standard deviation) for ongoing and past mental health variables. The PHQ-9 and GAD-7 total scores used to describe current psychological distress were calculated based on instrument guidelines for clinical thresholds. Lifetime past mental health variables included previous treatment such as hospitalization, counseling, medications, nonsuicidal self-injurious behavior, suicidal thoughts and behaviors, sexual assault, and other traumatic experiences. We used descriptive analyses to report the percentage of students indicating that they had experienced these past mental health variables prior to college, after starting college, or both.

\section{RESULTS}

Tables 1, 2, and 3 describe the means, standard deviations, and range of scores for the data on continuous mental health variables and reports on proportions for the categorical mental health variables. Descriptive results revealed that approximately $40 \%$ of students met the criteria for minimal depression, $13.5 \%$ for mild, $1.8 \%$ for moderate, and close to $1 \%$ for moderately severe.

As Table 1 indicates, $4.5 \%(n=5)$ of students screened positive for depression using the PHQ-9 score of $\geq 3(M=3.46, S D=3.01$, range $=0-16)$. The mean depression score for men was $3.9(S D=2.6$, range $=0-8)$. For women it was $3.2(S D$ $=2.9$, range $=0-16$ ). The most commonly reported depressive symptoms included lack of energy, sleep problems, and eating problems. Eating problems were defined as poor appetite or overeating.

Table 1: Depression Among Students Studying Abroad

\begin{tabular}{lcc}
\hline Variable & $n$ & $\%$ \\
\hline Severity (score) & & \\
\hline None (0) & 44 & 39.6 \\
Minimal (1-4) & 15 & 13.5 \\
Mild (5-9) & 2 & 1.8 \\
Moderate (10-14) & 1 & 0.9 \\
Moderately severe (15-19) & 0 & 0.0 \\
Severe (20-27) & & \\
\hline Individual items ( $\geq 1)$ & 22 & 20.0 \\
\hline Little to no pleasure & 33 & 29.7
\end{tabular}




\begin{tabular}{lcc}
\hline Variable & $n$ & $\%$ \\
\hline Sleep problems & 51 & 45.9 \\
Lack of energy & 48 & 67.6 \\
Eating problems (poor appetite or overeating) & 46 & 41.4 \\
Negative self-worth & 20 & 18.2 \\
Trouble concentrating & 24 & 21.8 \\
Physical movements (slow moving/speaking or being & 11 & 10.0 \\
$\quad$ fidgety/restless) & & \\
Suicidal ideation & 1 & 0.9 \\
\hline
\end{tabular}

In regard to anxiety (Table 2), the results revealed that $6.3 \%(n=7)$ scored $\geq 10$ on the GAD-7 $(M=2.62, S D=3.32$, range $=0-18)$. The most commonly reported symptoms included feeling anxious, becoming irritable, worrying about many different things, and trouble relaxing. The mean anxiety score for men was $2.5(S D=$ 3.1 , range $=0-10)$. For women, it was $3.9(S D=2.5$, range $=0-18)$.

Table 2: Anxiety Among Students Studying Abroad

\begin{tabular}{lcc}
\hline Variable & $n$ & $\%$ \\
\hline Severity (score) & & \\
\hline None (0) & 33 & 30.0 \\
Minimal (1-4) & 55 & 50.0 \\
Mild (5-9) & 15 & 13.6 \\
Moderate (10-14) & 5 & 5.5 \\
Moderately severe (15-21) & 1 & 0.9 \\
\hline Individual items ( $\geq 1)$ & & \\
\hline Feeling anxious & 49 & 44.1 \\
Unable to stop worrying & 24 & 21.8 \\
Worrying about many different things & 41 & 36.9 \\
Trouble relaxing & 37 & 33.3 \\
Restless, hard to sit still & 14 & 12.6 \\
Becoming irritable & 47 & 42.3 \\
Feeling afraid as if something awful might happen & 16 & 14.4 \\
\hline
\end{tabular}

Finally, Table 3 presents information regarding percentage and frequency of past mental health variables. One of the key findings in this area was that nearly $20 \%$ of the sample reported having participated in mental health counseling or treatment in the past (before and/or during college). Around 7\% reported taking psychiatric 
medications, with a similar percentage also reporting previous nonsuicidal selfinjurious behavior (e.g., cutting or burning without any suicidal intent). Finally, almost $12 \%$ of the respondents reported having experienced a traumatic event in their lives that caused significant psychological distress.

Table 3: Past Mental Health Variables Among Students Studying Abroad

\begin{tabular}{lcc}
\hline Variable & $n$ & $\%$ \\
\hline Previously attended mental health counseling & 21 & 19.1 \\
Psychiatric medication(s) & 8 & 7.2 \\
Psychiatric hospitalization & 1 & 0.9 \\
Nonsuicidal, self-injurious behavior (e.g., cutting, hitting, & 8 & 7.2 \\
$\quad$ burning, etc.) & & \\
Suicidal ideation & 5 & 4.5 \\
Suicide attempt & 2 & 1.8 \\
Unwanted sexual contact(s) or experience(s) & 9 & 8.1 \\
Traumatic experience & 13 & 11.7 \\
\hline
\end{tabular}

\section{DISCUSSION}

This study explored mental health in relation to depression and anxiety in a sample of U.S. college students studying abroad in Italy. Results demonstrated that students studying abroad had relatively low clinical diagnostic thresholds for psychological distress. Although average composite scores were low for depression and anxiety, there were individual symptoms that seemed to affect students abroad. It appears that a greater proportion of students abroad experienced sleeping and eating problems (poor appetite or overeating), irritability, and general feelings of anxiety or anxious thinking. These findings are in line with previous literature (e.g., Lindsey $\&$ Struve, 2008; Lucas, 2009) where similar observations are presented by the study-abroad personnel. The findings in this study also parallel results from nonclinical samples of college students in the United States. For instance, according to American College Health Association's (2012) National College Health Assessment, over half of college students surveyed felt overwhelmed, nearly a quarter had "felt very sad," and approximately half "felt exhausted- not from physical activity" in the past 2 weeks.

Findings from this exploratory, descriptive study offer service-oriented implications as well as direction for future research. Study abroad professionals are not always aware of pre-existing mental health conditions among their students due to a variety of factors such as stigma around mental health, privacy laws restricting shared information between counselors or mental health professionals and staff, and belief that professional assistance is not necessary (Holvey-Bowles et al., 2006). Confidentiality laws often prohibit study abroad staff from accessing students' medical records. Anonymous and brief mental health screenings (such as the PHQ-9 or GAD-7) may represent a suitable alternative in order to provide a general needs- 
based assessment for students and also assist in increasing students' level of awareness for mental health. Referrals for local services at the end of the screening can encourage student autonomy in seeking out counseling services to better prepare for a healthy and safe study abroad.

Based on the preliminary exploratory findings of this study, onsite psychological and counseling services may help alleviate the symptoms reported by students in this sample. Although it is not clear whether the most frequently reported symptoms are part of a larger clinical issue or related to adjustment difficulties, identifying and making counseling and psychological services readily available to all U.S. students abroad would be beneficial to the study abroad community. In some countries, counseling services for students are not as readily available as they are on home campuses. Cultural factors, including stigma and shame, may serve as barriers to students seeking mental health services in the United States and abroad. In addition, there are systematic barriers including the fact that onsite mental health professionals may not be covered under the students' insurance policies. Stigma and possible fear of reprisal for not reporting pre-existing conditions prior to the student's departure from the United States also might contribute to students' unwillingness to disclose and approach onsite staff for assistance in locating and seeking treatment from mental health professionals abroad. Although it is unclear what proportion of U.S. students studying abroad have pre-existing mental health issues, this research underscores the importance of providing psychological services for students abroad to assist them in successfully navigating a new academic environment, cultural adjustment, and, for some, lack of social support.

\section{Limitations and Suggestions for Future Research}

There are a few limitations to this research. This was a descriptive study and, as a result, no causal inferences can be made. The relatively low response rate (20\%) may suggest a reporting bias. It is important to consider that study abroad participants represent a particularly difficult population for research recruitment for several reasons, including the time and energy required to quickly adjust to a new academic environment and culture travel while abroad, and limited internet access in some regions. Readers also should note that the generalizability level in this study is another limitation, given that the small sample studying in one European country cannot adequately represent the overall population studying in Italy or in other countries.

Exploratory research provides hypothesis-generating outcomes. As such, the findings in this study provide direction for future research to examine mental health among college students abroad. Although larger probability-based sample sizes with quantitative study designs are particularly useful for generalizability, in-depth qualitative research designs should not be overlooked. Qualitative and mixedmethods research can provide a valuable contribution to this emerging area of research. For instance, this methodology could be used to explore students' and staff perspectives on mental health abroad, including current concerns, needs, and resources or coping mechanisms that have been useful. This type of research could also contribute to a better understanding of students' reasons for disclosing or choosing not to disclose previous mental health issues to staff prior to departure for 
study abroad as well as their willingness or reluctance to seek counseling while abroad so that programming could be designed to better support students.

\section{REFERENCES}

American College Health Association. (2012). Undergraduate students: Reference group data report: Spring 2012. https://www.acha.org/documents/ncha/ACHANCHA-II_UNDERGRAD_ReferenceGroup_DataReport_Spring2012.pdf

Barr, V., Rando, R., Krylowicz, B., \& Winfield, E. (2010). The Association for University and College Counseling Center Directors annual survey. http://files.cmcglobal.com/aucccd_directors_survey_monograph_2010_public.p df

Bathke, A., \& Kim, R. (2016). Keep calm and go abroad: The effect of learning abroad on student mental health. Frontiers: The Interdisciplinary Journal of Study Abroad, XXVII, 1-16.

Center for Collegiate Mental Health. (2010). CCAPS 2010 user manual. Penn State University Press.

Cranford, J., Eisenberg, D., \& Serras, A. M. (2009). Substance use behaviors, mental health problems, and use of mental health services in a probability sample of college students. Addictive Behaviors, 34, 134-145. doi:10.1016/j.addbeh.2008.09.004

Cushner, K. (2004). Beyond tourism: A practical guide to meaningful educational travel. Scarecrow Education.

Garlow, S. J., Rosenberg, J., Moore, J. D., Haas, A. P., Koestner, B., Hendin, H., \& Nemeroff, C. B. (2008). Depression, desperation, and suicidal ideation in college students: Results from the American Foundation for Suicide Prevention College Screening Project at Emory University. Depression and Anxiety, 25, 482-488. doi: 10.1002/da.20321

Holvey-Bowles, J., Lindeman, B., \& Scheib, M. (2006). Best practices in addressing mental health issues affecting education abroad participants. NAFSA: Association of International Educators. https://www.berry.edu/uploadedFiles/Website/Academics/Majors_and_Minors/ International_Programs/_Assets/Documents/Facultymental_health_NAFSA.pdf Hunley, H. (2010). Students' functioning while abroad: The impact of psychological distress and loneliness. International Journal of Intercultural Relations, 34, 386 392. https://doi.org/10.1016/j.ijintrel.2009.08.005

Hyun, J., Quinn, B., Madon, T., \& Lustig, S. (2007). Mental health need, awareness, and use of counseling services among international graduate students. Journal of American College Health, 56, 109-130. https://doi.org/10.3200/JACH.56.2.109118

Institute of International Education. (2018). Open doors report on international educational exchange. Retrieved September 24, 2018 from http:www.iee.org/opendoors

Kroenke, K., \& Spitzer, R. L. (2002). The PHQ-9: A new depression diagnostic and severity measure. Psychiatric Annals, 32, 509-521. https://doi.org/10.3928/0048-5713-20020901-06 
Kroenke, K., Spitzer, R. L., \& Williams, J. B. W. (2001). The PHQ-9: Validity of a brief depression severity measure. Journal of General Internal Medicine, 16, 606-613. https://doi.org/ 10.1046/j.1525-1497.2001.016009606.x

Lindeman, B. (Ed.). (2016). Addressing mental health issues affecting education abroad participants. Association of International Educators. http://eap.ucop.edu/Documents/Health/Best\%20Practices\%20Mental\%20Healt h.pdf

Lindsey, J., \& Struve, U. (2008, Summer). Practical strategies for addressing mental health issues within study abroad [Presentation]. British Universities Transatlantic Exchange Association Conference, Belfast, Ireland. Retrieved September 28, 2011 from http://www.butex.ac.uk

Lucas, J. (2009). Over-stressed, overwhelmed, and over here: Resident directors and the challenges of student mental health abroad. Frontiers: The Interdisciplinary Journal of Study Abroad, 18, 187-216.

Martin, A., Rief, W., Klaiberg, A., Braehler, E. (2006). Validity of the Brief Patient Health Questionnaire Mood Scale (PHQ-9) in the general population. General Hospital Psychiatry, 28(1), 71-77.

McCabe, L. (2005). Mental health and study abroad: Responding to the concern. International Educator, 14, 52-57. Retrieved from https://www.nafsa.org/sites/default/files/ektron/files/underscore/InternationalEd ucator/EducationAbroadNovDec05.pdf

Mikulas, J., \& Jitka, S. (2019). Statistical analysis of study abroad experiences of international students in five major host countries of Europe. Journal of International Students, 9, 1-18. https://doi.org/10.32674/jis.v9il.262

Mori, S. (2000). Addressing the mental health concerns of international students. Journal of Counseling and Development, 78, 137-144. https://doi.org/10.1002/j.1556-6676.2000.tb02571.x

Murphy, R. (Director). (2010). Eat, pray, love [Film]. Sony Pictures

Penn, S. (Director). (2007). Into the wild [Film]. Paramount Vantage.

Ryan, M., \& Twibell, R. (2000). Concerns, values, stress, coping, health and educational outcomes of college students who studied abroad. International Journal of Intercultural Relations, 24, 409-435. https://doi.org/10.1016/S01471767(00)00014-6

Rudd, M. D., Goulding, J., \& Bryan, C. J. (2011). Student veterans: A national survey exploring psychological symptoms and suicide risk. Professional Psychology: Research and Practice, 42, 354-360. https://doi.org/10.1037/a0025164।

Sandhu, D. S. (1995). An examination of the psychological needs of the international students: Implication for counseling and psychotherapy. International Journal for Advancement of Counseling, 17, 229-239.

Spitzer, R. L., Kroenke, K., Williams, J. W. B., \& Lowe, B. (2006). A brief measure for assessing generalized anxiety disorder. Archives of Internal Medicine, 166, 1092-1097. doi: 10.1001/archinte.166.10.1092

Sumer, S., Poyrazli, P., \& Grahame, K. (2008). Predictors of depression and anxiety among international students. Journal of Counseling and Development, 86, 429. https://doi.org/10.1002/j.1556-6678.2008.tb00531.x 
Zivin, K., Eisenberg, D., Gollust, S. E., \& Golberstein, E. (2009). Persistence of mental health problems and needs in a college student population. Journal of Affective Disorders, 117, 180-185. doi: 10.1016/j.jad.2009.01.007

SENEL POYRAZLI, PhD, is a Professor of Counseling Psychology in Social Sciences and Psychology at Penn State Harrisburg. Her major research interests lie in the areas of psychosocial and academic adjustment of international students, and multicultural competency. Email: poyrazli@psu.edu

MICHAEL A. MITCHELL, MA, was a graduate student with Penn State Harrisburg at the time this research was conducted. His research thesis examined mental health, alcohol use and cultural adjustment among college students studying abroad.Email: mitchellm593@gmail.com 